\title{
Ten-year review of candidemia in a Canadian tertiary care centre: Predominance of non-albicans Candida species
}

\author{
Ghada N Al-Rawahi MD DTM\&H(London) D(ABMM) FRCPC ${ }^{1,2}$, Diane L Roscoe MD FRCPC ${ }^{2,3}$
}

GN Al-Rawahi, DL Roscoe. Ten-year review of candidemia in a Canadian tertiary care centre: Predominance of nonalbicans Candida species. Can J Infect Dis Med Microbiol 2013;24(3):e65-e68.

OBJECTIVE: To review the epidemiology and associated risk factors for candidemia at a tertiary care centre, in view of recent reports on the changing epidemiology of bloodstream infection due to Candida species.

METHODS: Between January 2000 and December 2009, patients with blood culture samples positive for Candida species were identified using the microbiology laboratory information system. Patient data were collected by retrospective chart review of clinical characteristics including demographic data, underlying medical diagnoses and risk factors.

RESULTS: A total of 266 candidemia episodes were included in the final analysis. Fifty-nine per cent of these episodes occurred in males and $51 \%$ were in patients $>60$ years of age. The most common risk factor for candidemia was previous antibiotic use (85\%). The most frequent species was Candida albicans (49\%), followed by Candida glabrata (30\%). C albicans was the predominant species in all study years with the exception of 2002, in which C glabrata was more frequent. The likelihood of recovering a non-albicans Candida species was found to be significantly associated with previous antifungal therapy $(\mathrm{P}=0.0004)$, immunosuppressive therapy $(\mathrm{P}=0.002)$, abdominal surgery $(\mathrm{P}=0.003)$ and malignancy $(\mathrm{P}=0.05)$. Mixed candidemia was found in 10 episodes (4\%); 80\% grew C albicans and C glabrata. Risk factors for mixed candidemia were not significantly different from those with monomicrobial candidemia.

CONCLUSION: $\mathrm{C}$ albicans remains the most commonly isolated species in this setting, consistent with findings from other Canadian centres. However, non-albicans Candida species were overall predominant. Mixed-species candidemia does not appear to be more prevalent in patients with identified risk factors.

Key Words: Candidemia; Epidemiology; Risk factors

$\mathrm{B}$ lood stream infections with Candida species in hospitalized patients are associated with substantial morbidity, mortality and health care costs (1).

Although Candida albicans is the predominant species, literature reports have noted an increase in the incidence of non-albicans Candida (NAC) infections over the past decade (2-6). Literature reports have associated this change with the use of azoles as prophylactic antifungal therapy (7). Risk factors for invasive candidiasis in adult intensive care settings have been identified, including prolonged length of stay, diabetes, renal failure, hemodialysis, the use of broad spectrum antibiotics, the presence of central venous catheters (CVC), total parenteral nutrition (TPN), immunosuppressive drugs including chemotherapy, underlying malignancy, severe acute pancreatitis, Candida colonization at multiple sites, surgery and transplantation (8). Surgery, sepsis, multifocal colonization and TPN are risk factors that contribute to the determination of a bedside 'Candida score' to select patients eligible for early antifungal treatment (9).

\section{Une analyse de la septicémie à Candida sur dix ans dans un centre de soins tertiaires canadien : la prédominance d'autres espèces que le Candida albicans}

OBJECTIF : Analyser l'épidémiologie et les facteurs de risque connexes de septicémie à Candida dans un centre de soins tertiaires, compte tenu des récents rapports sur l'évolution de l'épidémiologie des bactériémies causées par des espèces de Candida.

MÉTHODOLOGIE : Entre janvier 2000 et décembre 2009, les chercheurs ont déterminé les patients dont l'hémoculture était positive aux espèces de Candida au moyen du système d'information du laboratoire de microbiologie. Ils ont colligé les données à leur sujet au moyen de l'analyse rétrospective des caractéristiques cliniques contenues dans leur dossier, y compris les données démographiques, les diagnostics médicaux sous-jacents et les facteurs de risque.

RÉSULTATS : Au total, 266 épisodes de septicémie à Candida ont été inclus dans l'analyse finale. Cinquante-neuf pour cent d'entre eux s'étaient produits chez des hommes, et $51 \%$ chez des patients de plus de 60 ans. La prise antérieure d'antibiotiques était le principal facteur de risque de septicémie à Candida (85\%), et les espèces les plus fréquentes, le Candida albicans (49 \%), suivies du Candida glabrata (30\%). Le C albicans était l'espèce prédominante dans toutes les années d'étude, sauf en 2002, où il était détrôné par le C glabrata. La possibilité de dépister une autre espèce que le $\mathrm{C}$ albicans s'associait nettement à une thérapie antifongique antérieure $(\mathrm{P}=0,0004)$, à une thérapie immunosuppressive $(\mathrm{P}=0,002)$, à une chirurgie abdominale $(\mathrm{P}=0,003)$ et à une tumeur maligne $(P=0,05)$. Dans dix épisodes $(4 \%)$, les chercheurs ont observé une septicémie à Candida mixte, dont $80 \%$ d'association de $\mathrm{C}$ albicans et de $\mathrm{C}$ glabrata. Les facteurs de risque de septicémie à Candida mixte ne différaient pas de manière significative de ceux des septicémies à Candida monomicrobiennes.

CONCLUSION : Le C albicans demeure l'espèce la plus isolée dans ce contexte, ce qui correspond aux observations d'autres centres canadiens. Cependant, dans l'ensemble, les autres espèces que le $\mathrm{C}$ albicans étaient prédominantes. Les septicémies à Candida mixtes ne semblent pas plus prévalentes chez les patients ayant des facteurs de risque déterminés.

Characterizing the local epidemiology of candidemia is essential because susceptibility to antifungal agents varies among different species and the knowledge of local epidemiology is one of several factors to consider when choosing empirical therapy. The present study was conducted to determine the occurrence of candidemia, the distribution of Candida species and the associated risk factors over a 10-year period at a Canadian tertiary teaching hospital.

\section{METHODS}

The study was conducted at the Vancouver General Hospital (Vancouver, British Columbia), a 637-bed acute care tertiary care centre and the main provincial referral and teaching hospital, providing care for a broad range of patients, including bone marrow and solid organ transplants, a trauma and burn unit, cardiac, neurology and combined medical-surgical intensive care unit (ICU), with more than 25,000 patient discharges annually. The present study was approved by the University of British Columbia Ethics Review Board (H03-70407) and the Vancouver Coastal Health Research Institute (V03-0185).

${ }^{1}$ Department of Pathology and Laboratory Medicine, Children's and Women's Health Centre of British Columbia; ${ }^{2}$ Department of Pathology and Laboratory Medicine, University of British Columbia; ${ }^{3}$ Department of Pathology and Laboratory Medicine, Vancouver General Hospital,

Vancouver, British Columbia

Correspondence: Dr Ghada N Al-Rawahi, BC Children's Hospital, Room 2G27-4500 Oak Street, Vancouver, British Columbia V6H 3N1.

Telephone 604-875-2394, fax 604-875-3777, e-mail ghada.al-rawahi@cw.bc.ca 
TABLE 1

Patient demographics $(n=266)$

\begin{tabular}{lc}
\hline Characteristic & $\mathbf{n}(\%)$ \\
\hline Sex & \\
$\quad$ Male & $157(59)$ \\
Female & $109(41)$ \\
Age, years & \\
$<30$ & $18(7)$ \\
$30-60$ & $111(42)$ \\
$>60$ & $137(51)$ \\
\hline
\end{tabular}

TABLE 2

Risk factors of patients with candidemia $(n=266)$

\begin{tabular}{lc}
\hline Risk factor & $\mathbf{n}(\%)$ \\
\hline Central venous catheter & $192(72)$ \\
Total parenteral nutrition & $77(29)$ \\
Antifungal therapy & $36(14)$ \\
Antibiotic therapy & $227(85)$ \\
Malignancy & $90(34)$ \\
Neutropenia & $31(12)$ \\
Transplantation & $29(11)$ \\
Immunosuppressive therapy & $37(14)$ \\
Steroid therapy & $44(17)$ \\
Intensive care unit admission & $101(38)$ \\
Burn & $7(3)$ \\
Dialysis & $19(7)$ \\
Abdominal/pelvic surgery & $83(31)$ \\
Other procedures* & $18(7)$ \\
\hline
\end{tabular}

*Other procedures included endoscopic retrograde cholangiopancreatography $(n=8)$, esophagogastroduodenoscopy $(n=2)$, colonoscopy $(n=2)$, cholangiogram $(n=1)$, bilateral nephrostomy tube change $(n=1)$, percutaneous nephrolithotripsy and ureteroscope $(n=1)$, ultrasound guided drainage $(n=1)$, bladder biopsy $(n=1)$, ureteroscope, lithotripsy and ureter stent $(n=1)$

Patients with candidemia between January 2000 and December 2009 were identified using the microbiology laboratory database. The medical records for each patient with candidemia were reviewed retrospectively. Baseline characteristics included age, sex, underlying diagnosis, surgical procedures, and bone marrow or solid organ transplantation. Information regarding additional potential risk factors for the development of candidemia included the presence of indwelling CVC, previous antibiotic and antifungal use, immunosuppressant agents (including steroids), underlying malignancy, neutropenia, ICU admission, TPN, burns and dialysis. Antibiotic and antifungal use, therapeutic or prophylactic, was documented if administered for more than $24 \mathrm{~h}$

\section{Organism identification}

Blood cultures were monitored using an automated culture system (Bactec 9240 System, Becton Dickinson, USA) and were incubated for five days. Candida species were identified using conventional methods including germ tube, Auxacolor (Sanofi Diagnostics Pasteur, France), cornmeal morphology, chromogenic agar (Oxoid chromogenic Candida agar) and a referral to a reference laboratory if required.

\section{Statistics}

Association tests on contingency tables were calculated using Fisher's exact test using GraphPad software (GraphPad, USA) (10). Results were considered to be statistically significant at $\mathrm{P}<0.05$.

\section{RESULTS}

A total of 298 episodes of candidemia were identified during the study period, with an incidence rate of 1.3 per 10,000 patient days. Thirty-two episodes were excluded due to unavailability of medical records;

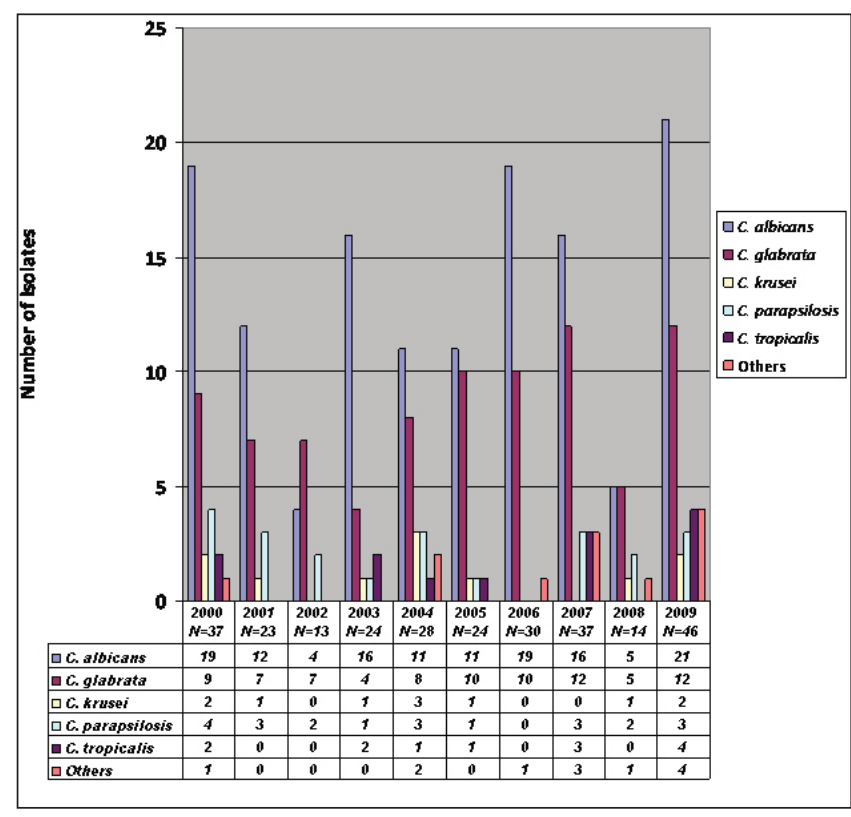

Figure 1) Distribution of Candida species according to year

therefore, 266 episodes were included in the final analysis. Fifty-nine per cent of the episodes occurred in males and $51 \%$ were in patients $>60$ years of age (Table 1 ). The most common risk factor for candidemia was previous antibiotic use (85\%). Indwelling CVC, including peripherally inserted central catheters, were present in the majority of episodes (72\%) (Table 2).

The most frequently isolated species in the study period (Figure 1) was C albicans (49\%), followed by Candida glabrata (30\%), Candida parapsilosis (8\%), Candida tropicalis (5\%) and Candida krusei (4\%); the remaining $4 \%$ of cultures grew Candida lusitaniae (1\%), Candida dubliniensis (1\%), Candida guilliermondii (0.7\%), Candida kefyr $(0.4 \%)$, Candida inconspicua (0.4\%) and Candida lipolytica (0.4\%). C albicans was the predominant species in all study years with the exception of 2002, during which C glabrata was more frequent.

The likelihood of recovering a NAC species was found to be significantly associated with previous antifungal use $(6 \% \mathrm{C}$ albicans versus $21 \%$ NAC; $\mathrm{P}=0.0004$ ), immunosuppressive therapy (7\% C albicans versus $21 \% \mathrm{NAC}$; $\mathrm{P}=0.002$ ), malignancy ( $29 \% \mathrm{C}$ albicans versus $41 \%$ NAC; $\mathrm{P}=0.05)$ and abdominal surgery (22\% C albicans versus $40 \%$ NAC; $\mathrm{P}=0.003$ ).

Mixed-species candidemia (MC) (Figure 2) was found in 10 episodes (4\%): eight grew C albicans and C glabrata; one grew C albicans and $\mathrm{C}$ dubliniensis; and one grew $\mathrm{C}$ glabrata and $\mathrm{C}$ parapsilosis. Risk factors for mixed candidemia were not significantly different from those with monomicrobial candidemia: $80 \%$ versus $63 \%$ for CVC $(\mathrm{P}=0.44) ; 80 \%$ versus $88 \%$ for previous antibiotic use $(\mathrm{P}=0.62) ; 0 \%$ versus $17 \%$ for previous antifungal use $(\mathrm{P}=0.30) ; 10 \%$ versus $29 \%$ for abdominal surgery $(\mathrm{P}=0.39)$; and $0 \%$ versus $29 \%$ for underlying malignancy $(\mathrm{P}=0.08)$.

The patients in the present study recovered from candidemia with no immediate complications (58\%) or died (40\%), although the contribution of candidemia to the fatal outcome was not determined. The outcome in 2\% was not known: one patient left against medical advice, four were transferred to another facility and one patient was seen in emergency without follow-up admission.

\section{DISCUSSION}

The results of the present study were consistent with the literature, which reports $\mathrm{C}$ albicans as the predominant species recovered from patients with candidemia. In most parts of the world, $\mathrm{C}$ albicans accounts for between $40 \%$ and $70 \%$ of candidemia cases. However, species distribution varies throughout the world. For example, $\mathrm{C}$ albicans 
and $\mathrm{C}$ glabrata were the most frequently isolated species in United States, while $\mathrm{C}$ albicans and $\mathrm{C}$ parapsilosis were the most common species in Spain $(11,12)$. Within Canada, reports from Quebec $(13,14)$ showed that $\mathrm{C}$ albicans and $\mathrm{C}$ glabrata were the most common species while $\mathrm{C}$ albicans and $\mathrm{C}$ parapsilosis were most frequently isolated from an Ontario study (15). This variation may have resulted from the emergence of species intrinsically resistant to antifungal agents or species that developed resistance with use. Overall, the three most prevalent NAC species are $\mathrm{C}$ glabrata, $\mathrm{C}$ parapsilosis and $\mathrm{C}$ tropicalis (16-19).

Previous antifungal use was found to be significantly associated with the development of NAC. This association was also described by Chow et al (20). On the other hand, patients who had undergone cancer chemotherapy were not found to be at a higher risk for NAC despite previous reports (21).

When the non-neonatal pediatric population was studied, there was no significant difference between NAC and C albicans candidemia for age, previous antibiotic exposure, previous antifungal use, CVC days before the onset of candidemia and indwelling urinary catheters (6).

Chromogenic agar was included in the algorithm for blood cultures positive for yeasts in the Vancouver General Hospital laboratory in 2002 to facilitate the detection of mixed yeast cultures. During the study period, 10 episodes were identified as $\mathrm{MC}$ and all were detected from 2002 onward (Figure 2). Despite the 40\% figure in 2006, it is difficult to conclude that this is statistically significant based on the small numbers.

To characterize the risk factors associated with MC, each episode was compared with two to three control episodes of monomicrobial candidemia (24 controls). However, no significant difference was observed between the risk factors in the two groups. In contrast, Jensen et al (22) reported that patients with $\mathrm{MC}$ had more frequently undergone organ transplantation $(\mathrm{P}=0.04)$ and surgery $(\mathrm{P}=0.03)$, and lower rate of use of TPN $(\mathrm{P}=0.05)$.

The present study had several limitations. First was the possibility of selection bias resulting from the retrospective collection of risk factors data. Second, exposure to antibiotics or antifungal agents was considered to be risk factor if used for more than $24 \mathrm{~h}$ without collecting dosage and duration. Third, ICU stay was not calculated in the present study. It has been described that prolonged ICU stay represents

\section{REFERENCES}

1. Zaoutis TE, Argon J, Chu J, Berlin JA, Walsh TJ, Feudtner C. The epidemiology and attributable outcomes of candidemia in adults and children hospitalized in the United States: A propensity analysis. Clin Infect Dis 2005;41:1232-9.

2. Horn DL, Neofytos D, Anaissie EJ, et al. Epidemiology and outcomes of candidemia in 2019 patients: Data from the prospective antifungal therapy alliance registry. Clin Infect Dis 2009;48:1695-703.

3. Pappas PG, Rex JH, Lee J, et al. A prospective observational study of candidemia: Epidemiology, therapy, and influences on mortality in hospitalized adult and pediatric patients. Clin Infect Dis 2003;37:634-43.

4. Sipsas NV, Lewis RE, Tarrand J, et al. Candidemia in patients with hematologic malignancies in the era of new antifungal agents (2001-2007): Stable incidence but changing epidemiology of a still frequently lethal infection. Cancer 2009;115:4745-52.

5. Bassetti M, Righi E, Costa A et al. Epidemiological trends in nosocomial candidemia in intensive care. BMC Infect Dis 2006;6:21.

6. Dutta A, Palazzi DL. Candida non-albicans versus Candida albicans fungemia in the non-neonatal pediatric population. Pediatr Infect Dis J 2011;30:664-8.

7. Lortholary O, Desnos-Ollivier M, Sitbon K, et al. French Mycosis Study Group. Recent exposure to caspofungin or fluconazole influences the epidemiology of candidemia: A prospective multicenter study involving 2,441 patients. Antimicrob Agents Chemother 2011;55:532-8.

8. Ostrosky-Zeichner L, Pappas PG. Invasive candidiasis in the intensive care unit. Crit Care Med 2006;34:857-63.

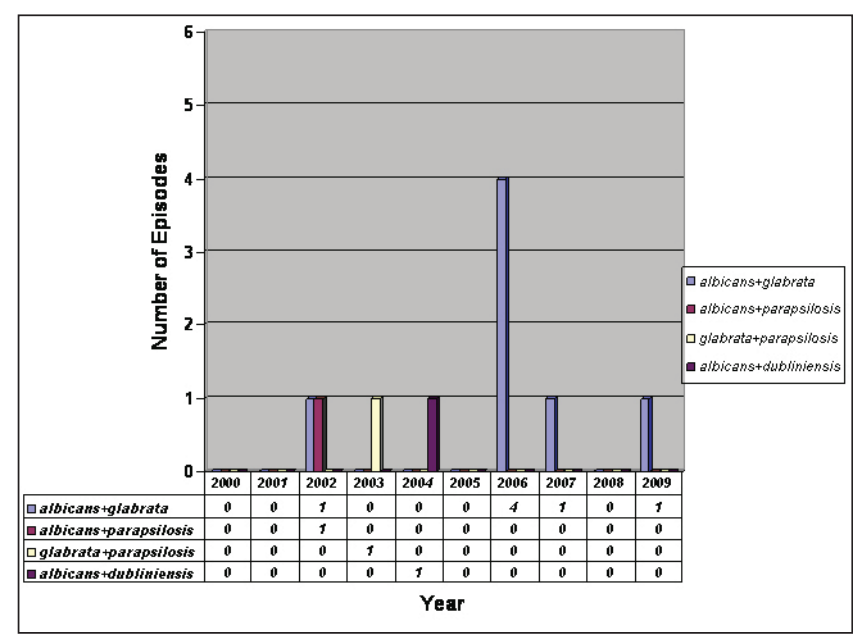

Figure 2) Distribution of mixed-species candidemia according to year

an important risk factor for candidemia in critically ill patients, with the incidence of candidemia peaking at approximately day 8 to $10(23,24)$.

\section{CONCLUSION}

C albicans remains the most commonly isolated species in our tertiary care hospital setting, consistent with findings from other Canadian centres. However, NAC species were predominant overall. MC does not appear to be more prevalent in patients with identified risk factors.

FUNDING: This work was not supported by any funding agencies.

DISCLOSURES: The results from the first seven years of this study were presented at the AMMI Canada-CACMID 2008 Annual Conference. The study was conducted at Vancouver General Hospital, Vancouver, British Columbia. Ghada N Al-Rawahi and Diane L Roscoe have no conflicts of interest related to the work in this study.

9. Leon C, Ruiz-Santana S, Saavedra P, et al. A bedside scoring system ('Candida score') for early antifungal treatment in non-neutropenic critically ill patients with Candida colonization. Crit Care Med 2006;34:730-7.

10. http://graphpad.com/quickcalcs/index.cfm (Accessed September 25, 2012).

11. Pfaller MA, Diekema DJ. Epidemiology of invasive candidiasis: A persistent public health problem. Clin Microbiol Rev 2007;20:133-63.

12. Ortega M, Marco F, Soriano A, et al. Candida species bloodstream infection: Epidemiology and outcome in a single institution from 1991 to 2008. J Hosp Infect 2011;77:157-61.

13. Labbé AC, Pépin J, Patiño C, Castonguay S, Restieri C, Laverdiere M. A single-centre 10-year experience with Candida bloodstream infections. Can J Infect Dis Med Microbiol 2009;20:45-50.

14. St-Germain G, Laverdière M, Pelletier R et al. Epidemiology and antifungal susceptibility of bloodstream Candida isolates in Quebec: Report on 453 cases between 2003 and 2005. Can J Infect Dis Med Microbiol 2008;19:55-62.

15. Maganti H, Yamamura D, Xu J. Prevalent nosocomial clusters among causative agents for candidemia in Hamilton, Canada. Med Mycol 2011;49:530-8.

16. Chi HW, Yang YS, Shang ST, et al. Candida albicans versus nonalbicans bloodstream infections: The comparison of risk factors and outcome. J Microbiol Immunol Infect 2011;44:369-75.

17. Poikonen E, Lyytikäinen O, Anttila VJ, et al. Secular trend in candidemia and the use of fluconazole in Finland, 2004-2007. BMC Infect Dis 2010;10:312. 
18. Jung SI, Shin JH, Song JH, et al. Korean Study Group for Candidemia. Multicenter surveillance of species distribution and antifungal susceptibilities of Candida bloodstream isolates in South Korea. Med Mycol 2010;48:669-74.

19. Bow EJ, Evans G, Fuller J, et al. Canadian clinical practice guidelines for invasive candidiasis in adults. Can J Infect Dis Med Microbiol 2010;21:e122-50.

20. Chow JK, Golan Y, Ruthazer R, et al. Factors associated with candidemia caused by non-albicans Candida species versus Candida albicans in the intensive care unit. Clin Infect Dis 2008;46:1206-13.

21. Cheng MF, Yang YL, Yao TJ, et al. Risk factors for fatal candidemia caused by Candida albicans and non-albicans Candida species. BMC Infect Dis 2005;5:22.
22. Jensen J, Muñoz P, Guinea J, Rodríguez-Créixems M, Peláez T, Bouza E. Mixed fungemia: Incidence, risk factors, and mortality in a general hospital. Clin Infect Dis 2007;44:e109-14.

23. McKinnon PS, Goff DA, Kern JW, et al. Temporal assessment of Candida risk factors in the surgical intensive care unit. Arch Surg 2001;136:1401-8.

24. Garbino J, Lew DP, Romand JA, Hugonnet S, Auckenthaler R, Pittet D. Prevention of severe Candida infections in nonneutropenic, high-risk, critically ill patients: A randomized, doubleblind, placebo-controlled trial in patients treated by selective digestive decontamination. Intensive Care Med 2002;28:1708-17. 


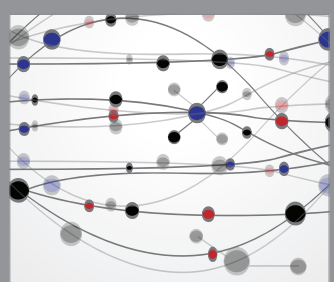

The Scientific World Journal
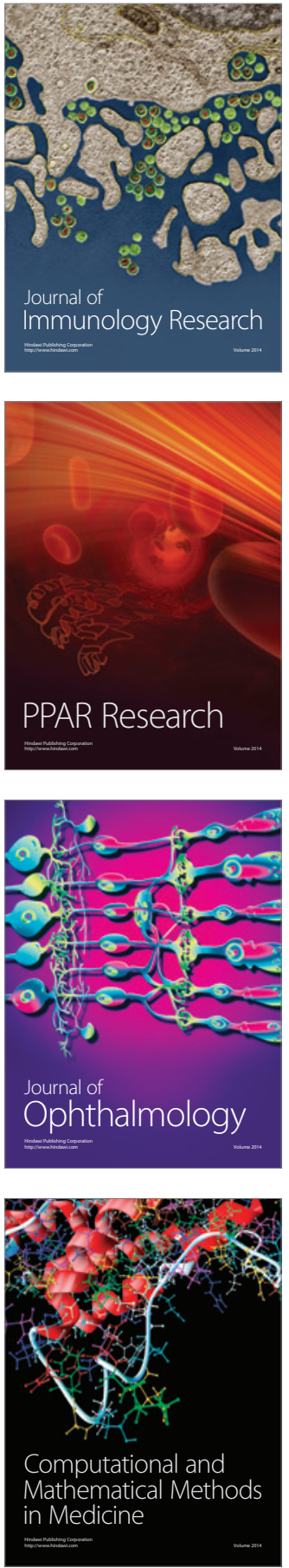

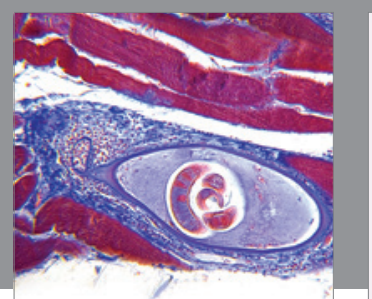

Gastroenterology Research and Practice

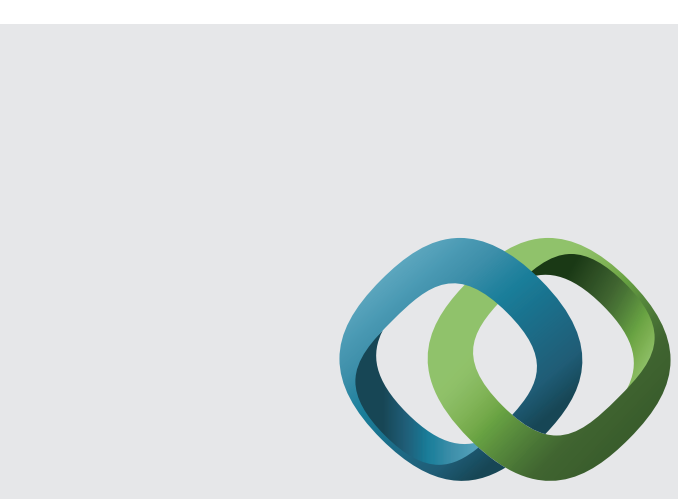

\section{Hindawi}

Submit your manuscripts at

http://www.hindawi.com
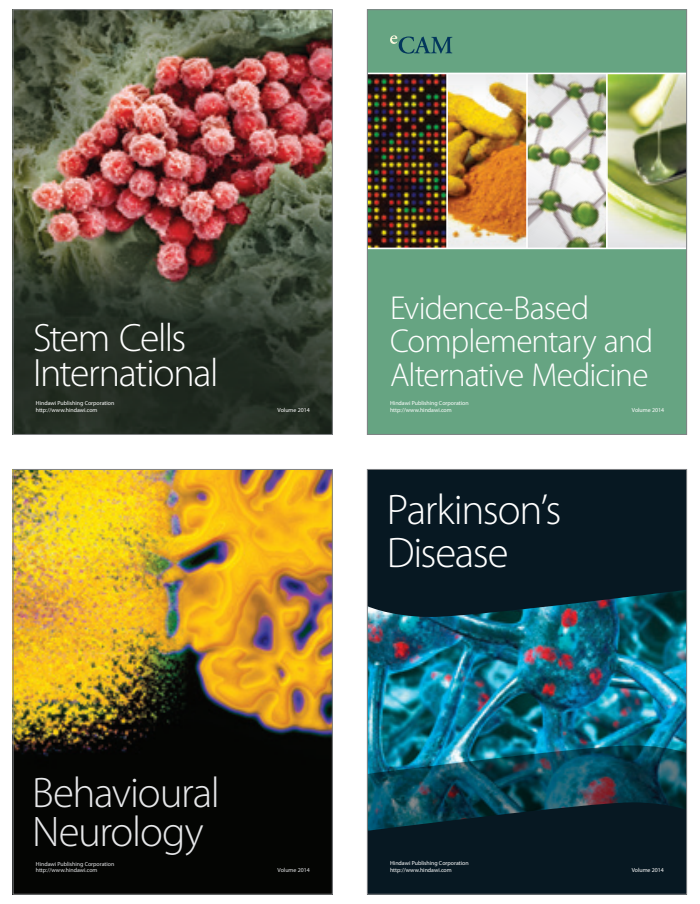
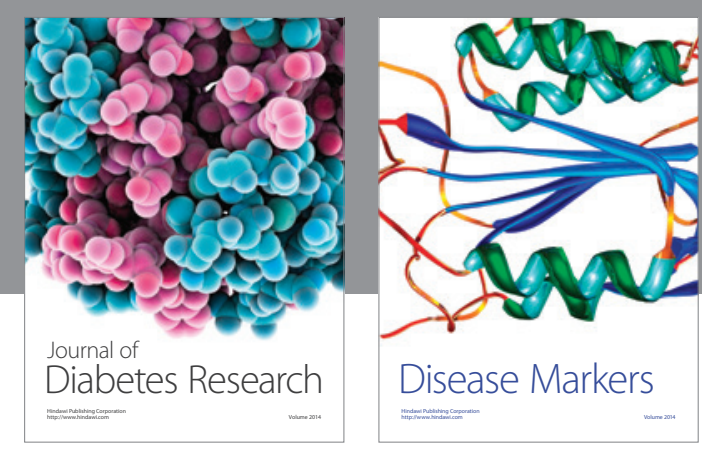

Disease Markers
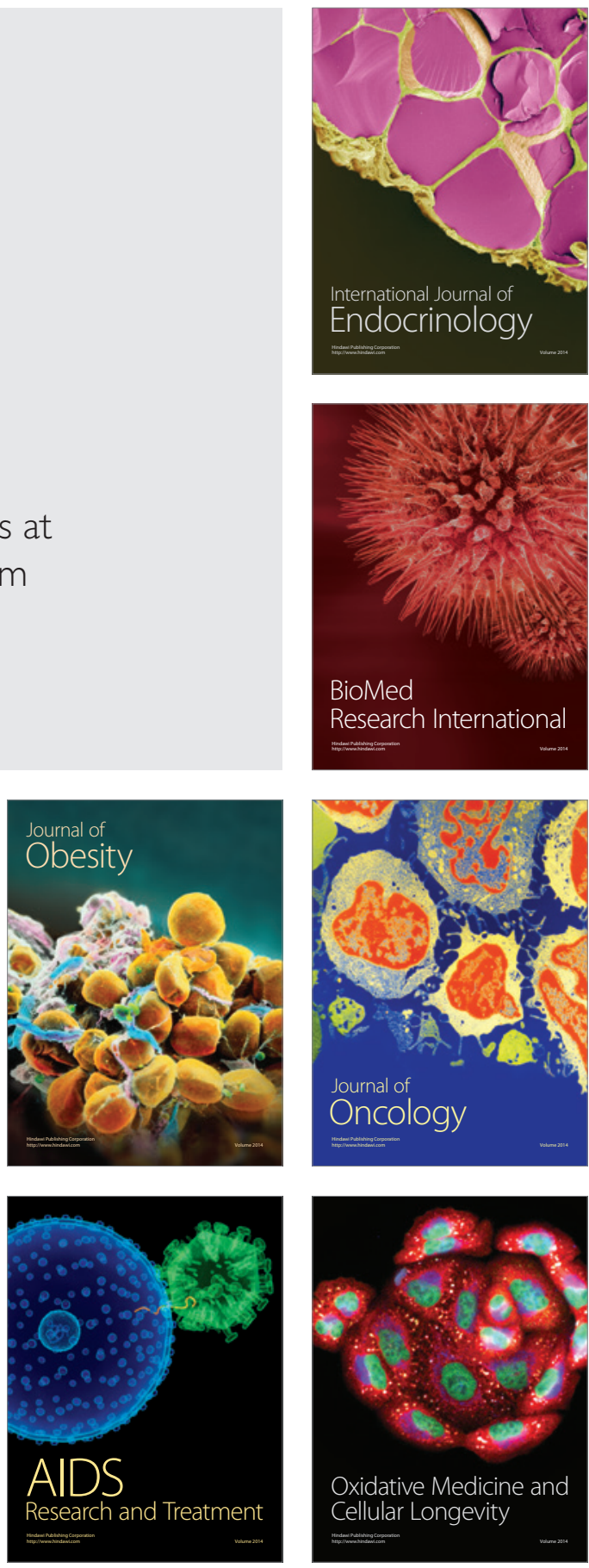